Original Paper

\title{
Sosialisasi Tentang Mitigasi Bencana Tsunami dan Gempa Lombok Di Jempong Baru, Sekarbela, Mataram
}

\author{
Muhammad Zuhdi ${ }^{1 *}$, Mukh Makhrus ${ }^{1}$, Sutrio $^{1}$, Wahyudi ${ }^{1}$ \\ ${ }^{1}$ Program studi pendidikan fisika, Fakultas Keguruan dan Ilmu Pendidikan, Universitas Mataram, Indonesia
}

DOI: 10.29303/jpmpi.v2i1.316

Sitasi: Zuhdi, et, al. (2019). Sosialisasi Tentang Mitigasi Bencana Tsunami dan Gempa Lombok Di Jempong Baru, Sekarbela, Mataram. Jurnal Pengabdian Magister Pendidikan IPA (JPMPI). (2) 1. pp. 6-7

*Corresponding Author: Muhammad Zuhdi, Program studi pendidikan fisika, Fakultas Keguruan dan Ilmu Pendidikan, Universitas Mataram, Indonesia; Email: mzuhdi@unram.ac.id

\begin{abstract}
Abstrak: Bencana Gempa bumi di pulau Lombok yang terjadi secara berturut-turut sejak bulan Juli 2018 sampai akhir 2018, telah menimbulkan sejumlah korban harta benda dan korban jiwa. Sebanyak 209 jiwa telah terenggut pada saat kejadian gempa ini, sedangkan kerusakan infrastuktur dan bangunan diperkirakan mencapai nilai kerugian hingga 300 milyar rupiah. Gempa ini juga telah menimbulkan terjadinya keretakan pada tanah dan longsor pada beberapa tempat di sekitar Gunung Rinjani. Gempa bumi yang disertai gelombang tsunami yang telah menelan hingga puluhan ribu korban jiwa di Aceh adalah merupakan gempa bumi dengan jumlah korban terbanyak dalam kurun 45 tahun terakhir. Gempa terbesar sebelumnya pernah terjadi di Peru, pada tahun 1970 dengan korban sebanyak 120.000 jiwa. Gempa bumi yang diikuti tsunami dan likwifaksi juga telah menghancurkan sebagian kota di daerah pantai di Palu. Likwifaksi dan tsunami yang terjadi sebagai bencana sekunder di Palu telah menelan korban yang jauh lebih banyak dibandingkan bencana primernya. Kekhawatiran masyarakat Lombok akan terjadinya gempa dan tsunami dengan kekuatan yang jauh lebih besar lagi justru akan menyulitkan warga masyarakat untuk segera bangkit kembali pasca gempa besar yang telah terjadi di Pulau Lombok. Untuk itu, maka perlu dilakukan upaya sosialisasi yang akan membuat masyarakat lebih paham terhadap resiko jika suatu saat terjadi bencana alam dan juga mengurangi kekhawatiran yang berlebihan akibat pemahaman yang kurang pada masalah bencana. Oleh sebab itu maka perlu dilakukan upaya pemecahan masalah ini, melaui sosialisasi tentang mitigasi bencana. Hasil sosialisasi ini telah membuat masyarakat menjadi faham tentang resiko bencana, cara menanggulanginya dan menghilangkan kekhawatiran yang berlebihan.
\end{abstract}

Keywords: Sosialisasi; Mitigasi; Gempa; Tsunami.

\section{Pendahuluan}

Gempa bumi disertai gelombang tsunami yang menelan puluhan ribu korban meninggal di Aceh merupakan gempa dengan jumlah korban terbanyak dalam 35 tahun terakhir. Gempa terdahsyat sebelumnya terjadi di Peru, tahun 1970 dengan menelan korban sebanyak 120.000 jiwa. Gempa Palu dan Gempa Lombok tahun 2018 juga merupakan bencana gempa dengan total kerugian yang sangat besar.

Bencana sekunder dari gempa -berupa longsor, tsunami- maupun likwifaksi biasanya menelan lebih banyak korban dibandingkan dengan bencana primer yaitu goncangan gempa itu sendiri. Tsunami sebagai bencana sekunder dari gempa di Aceh dan Sumatra Utara telah menelan jauh lebih banyak korban dibandingkan bencana primernya. Likwifaksi dan tsunami di Palu juga menelan korban yang cukup besar.

Sebelum terjadinya bencana Tsunami Aceh, setidaknya dalam lima tahun terakhir telah terjadi empat bencana tsunami besar di Indonesia, yaitu di Flores 12 Desember 1992, Banyuwangi 3 Juni 1994 dan Biak 17 Februari 1996 , Sulawesi Tengah. Dalam satu abad terakhir setidaknya telah terjadi 
tujuh belas bencana tsunami di Indonesia. Bencana tsunami tersebut setidaknya telah menimbulkan kerugian materi triliunan rupiah dan hilangnya ratusan ribu jiwa manusia. Bencana gempa kerap terjadi di Indonesia karena posisinya yang berada pada Ring of Fire. Peta zona rawan tsunami di pulau Lombok dengan pemodelan computer berbasis MatLab sudah pernah dibuat di dipublikasikan (Zuhdi, dkk. 2012). Peta zona rawan amplifikasi dengan metode microtremor juga pernah di buat untuk Pulau Lombok. (Syamsuddin, dkk 2018). Model Sesar Pasca Gempa juga pernah dibuat untuk memahami mekanisme gempa (Zuhdi, dkk., 2019)

Pulau Lombok memiliki potensi yang sama untuk terjadinya gempa tektonik seperti yang terjadi di Aceh. Sebagaimana Sumatra dan Jawa, Lombok berada pada zona subduksi, yaitu daerah dimana terjadi tumbukan antara dua buah lepeng. Zona ini merupakan daerah dimana gempa sangat sering terjadi. Gempa Lombok tahun 2018 telah membuktikan hal ini.

Pada zona subduksi dapat terjadi ratusan gempa dalam satu tahun, dengan magnitudo yang bervariasi. Gempa dengan magnitudo kecil lebih sering terjadi, gempa berkekuatan sedang lebih jarang terjadi. Sedangkan gempa dengan kekuatan besar seperti yang baru saja terjadi di Aceh, sangat jarang terjadi. Gempa dengan kekuatan setara memiliki periode siklus sekitar 200 tahun.

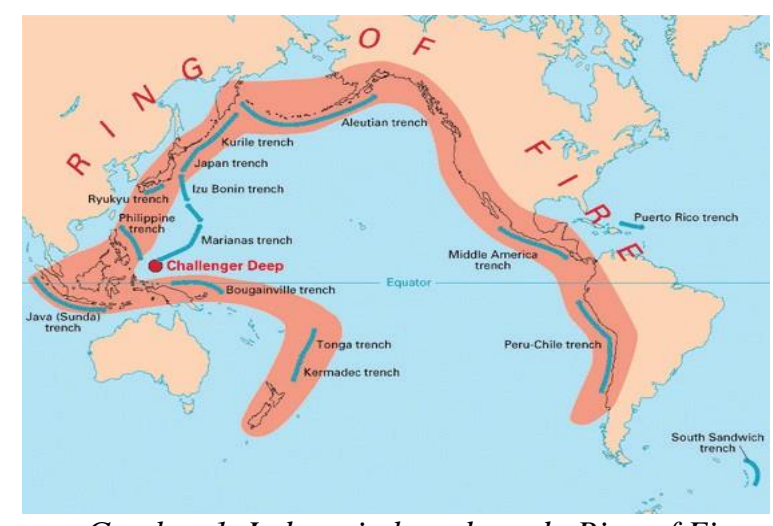

Gambar 1. Indonesia berada pada Ring of Fire.

Banyaknya korban jiwa pada bencana tsunami lebih dikarenakan "kejutan" dan ketidaksiapan dalam menghadapinya. Secara statistik akibat dari bencana berupa "kejutan" semacam ini hanya akan menyisakan korban selamat dalam prosentase yang kecil. Dalam aktivitas keseharian, warga langsung dihadapkan dengan air dengan kecepatan tinggi dengan jumlah yang besar. Apabila warga sebelumnya mendapat peringatan, maka korban jiwa oleh bencana ini dapat diminimalkan.

Salah satu upaya mitigasi bencana tsunami adalah menginformasikan kepada masyarakat akan posisi mereka terhadap kemungkinan bahaya bencana longsor, tsunami.maupun likwifaksi. Informasi tersebut berupa berbagai besaran fisis yang berkaitan dengan intensitas kerusakan yang mungkin ditimbulkan oleh bencana sekunder akibat gempa tersebut.

Gempa juga dapat memicu tanah longsor maupun likuifaksi. Kondisi fisis material tanah dan besarnya getaran sangat menentukan potensi lonsor akibat gempa. (Boomer, Rodriguez, 2002, Mahdavifar, dkk, 2006, Rafice, Capolongo, 2002).

Kekhawatiran masyarakat NTB akhir-akhir ini terhadap akan datangnya gempa dan tsunami yang lebih besar justru akan menyulitkan masyarakat untuk bangkit kembali setelah gempa besar yang melanda Pulau Lombok beberapa bulan lalu. Untuk itu perlu dilakukan sosialisasi yang membuat masyarakat menjadi lebih paham resiko jika terjadi bencana alam dan mengurangi kekhawatiran berlebihan akibat kurangnya pemahaman masalah bencana. Untuk itu maka perlu dilakukan pemecahan masalah melaui sosialisasi mitigasi bencana.

Kekhawatiran yang sama juga terjadi pada pertengahan bulan Agustus 2018, saat munculnya isu akan datangnaya gempa dan tsunami besar pada tanggal 26 Agustus 2018. Banyak anggota masyarakat yang berencana melakukan eksodus keluar Pulau Lombok secara bersamaan, padahal urgensinya sangat tidak beralasan. Oksodus ini akan menimbulkan dampak psikis maupun ekonomi yang akan banyak merugikan masyarakat Lombok. Sebagai seorang akademisi yang merasa punya tanggung-jawab terhadap masyarakat, maka penulis memberi penjelasan untuk menenangkan masyarakat, melalui media social. Penjelasan tersebut diposting pada tanggal 24 Desember 2018 dan langsung tersebar dengan cepat. Berikut adalah isi postingan tersebut:

\section{Assalaamualaikum wr wb.}

Akhir-akhir ini beredar kabar yang mengatakan bahwa esok pagi, hari Ahad, tgl 26 Agustus2018, pulau Lombok akan di guncang gempa besar dan tsunami. Informasi tsb sayangnya sangat dipercayai oleh sebagian masyarakat Lombok, bahkan beberapa diantaranya akan 
mengungsi menjauhi tepi pantai bahkan meninggalkan pulau Lombok.

Informasi ramalan ini sangat menyesatkan dan berpotensi merugikan warga masyarakat Lombok.

Faktanya bahwa hingga saat ini gempa dan tsunami secara ilmiah tidak dapat diprediksi hingga hitungan tanggal.

Memang ada beberapa bencana besar yang terjadi di tgl 26, namun jumlahnya hampir sama dengan bencana besar yang jatuh di tanggal lain semisal tanggal 15 atau 20. Bencana yang datang di hari minggu juga hampir sama banyaknya dengan bencana yang datang di hari lain, misalnya senin atau selasa. Ini menunjukkan bahwa tidak ada kaitan antara tanggal dan hari tertentu dengan datangnya bencana besar. Parameter fisis gempa dan tsunami juga tidak berkaitan dengan tanggal dan hari.

Kesimpulannya adalah bahwa hari minggu tgl 26 Agustus tidak akan terjadi gempa besar maupun tsunami. Mengungsi dan keluar dari pulau Lombok adalah hal yang sia-sia dan tidak perlu dilakukan. Yang penting bagi kita adalah tetap waspada, istighfar dan memohon pada Allah agar selalu dijauhkan dari segala musibah.

Jika berkenan silahkan dishare untuk memberi informasi yang benar dan menenangkan bagi masyarakat.

Alhamdulillah, 100 jam terakhir ini, menurut data USGS, tidak ada lagi gempa melebihi 2,5 SR dengan episenter di daratan Lombok. Kita berdoa semoga bencana gempa di Lombok benarbenar barakhir.

Wallahua'lam.

Wassalaamualaikum wr. wb.

Salam hormat.

Muhammad Zuhdi

(Dosen Geofisika Universitas Mataram, peneliti kegempaan dan tsunami).

Pada tanggal 25 Desember 2018, sehabis sholat isyak, penulis sengaja mengumpulkan warga masyarakat untuk memberi penjelasan ilmiah tentang ramalan gempa yang akan terjadi di tanggal 26 Agustus tersebut. Penjelasan tersebut telah berhasil menenangkan warga masyarakat. Hasilnya, mereka yang sedianya akan segera mengungsi karena meyakini akan datangnya bencana, kemudian memutuskan untuk tidak mengungsi karena sudah merasa paham dengan informasi yang benar dan hilang rasa khawatir yang berlebih.
Tujuan dari kegiatan pengabdian ini adalah meningkatkan pemahaman masyarakat akan bahaya dan resiko bencana longsor, likuifaksi dan tsunami akibat gempa serta mitigasinya.

Sedangkan manfaat dari kegiatan pengabdian ini adalah untuk meningkatkan pemahaman masyarkat sehingga dapat menghilangkan kekhawatiran berlebih dan meningkatkan semangat masyarakat untuk kembali bangkit setelah bencana gempa.

\section{Metode Pelaksanaan}

Masalah yang terjadi di masyarakat NTB pada umumnya dan masyarakat Lombok pada khususnya adalah kekhawatiran berlebih terhadap akan datangnya gempa dan tsunami yang lebih besar. Kekhawatiran ini justru akan menyulitkan masyarakat untuk bangkit kembali setelah gempa besar yang melanda Pulau Lombok beberapa bulan lalu. Untuk itu perlu dilakukan sosialisasi yang membuat masyarakat menjadi lebih paham resiko jika terjadi bencana alam khususnya gempa dan bencana sekundernya dan mengurangi kekhawatiran berlebihan akibat kurangnya pemahaman masalah bencana tersebut. Untuk itu maka perlu dilakukan pemecahan masalah melaui sosialisasi mitigasi bencana.

Berdasarkan masalah yang dialami oleh warga masyarakat, maka usaha yang dilakukan untuk memecahkan masalah tersebut adalah dengan memberikan kegiatan sosialisasi yang membuat masyarakat menjadi lebih paham resiko jika terjadi bencana alam dan mengurangi kekhawatiran berlebihan akibat kurangnya pemahaman masalah bencana. Untuk itu maka perlu dilakukan pemecahan masalah melaui sosialisasi mitigasi bencana.

Pengabdian Masyarakat ini dilaksanakan dalam bentuk seminar yang terdiri dari dua tahap yaitu: tahap pertama, penjelasan pemahaman mekanisme terjadinya bencana gempa dan bencana sekundernya melalui metode ceramah dan presentasi dengan animasi serta video. Tahap kedua, dilakukan dengan metode ceramah/diskusi tentang mitigasi dan upaya penyelamatan saat dan setelah terjadinya gempa.

Kegiatan pengabdian pada masyarakat ini secara efektif dilakukan selama 8 bulan terhitung dari tanggal April sampai dengan September 2019. 
Puncak acara kegiatan pengabdian pada masyarakat ini dilakukan pada tanggal 3 Agustus 2019.

Kegiatan dimulai dengan ceramah tentang bencana gempa bumi, tsunami, longsor dan likuifaksi disertai dengan penjelasan ilmiah mekanisme terjadinya bencana-bencana tersebut.

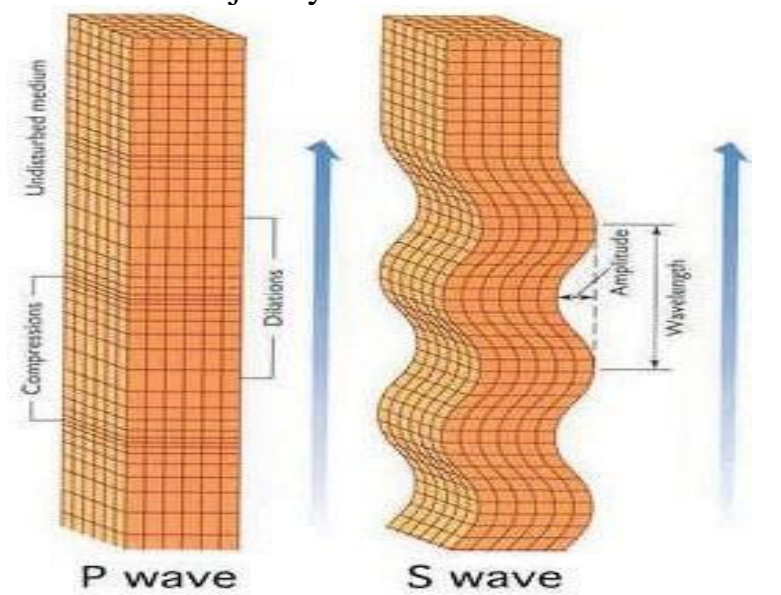

Gambar 2. Contoh media yang menjelaskan penjalaran gelombang gempa

Penjelasan disampaikan dengan bahasa awam yang mudah dipahami oleh audiens yang terdiri dari orang-orang dewasa, remaja dan juga anak-anak, Penjelasan disampaikan dengan analogi sederhana yang mudah dipahami oleh audiens. Pada tahap ini juga dilakukan pemutaran video tentang gempa bumi tsunami likuifaksi dan tanah longsor. Inti dari kegiatan ini didasarkan pada penggunaan media pembelajaran dengan menggunakan perangkat penunjang computer (Kusnadi dan Sutjipt, 2013, Roestiyah, 2001).

Ceramah dilakukan dengan bantuan media TV berukuran 32 inci dengan software pendukung yaitu Microsoft PowerPoint. Video tentang gempa dan tsunami serta likuifaksi juga diputar pada media televisi tersebut.

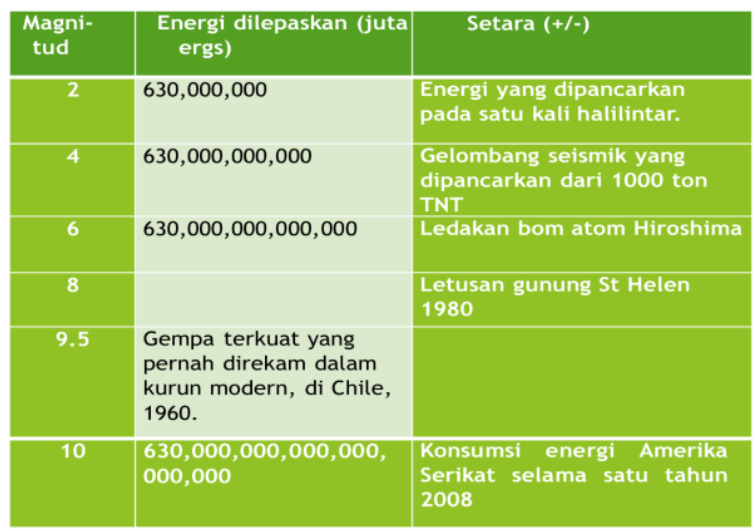

Gambar 3. Contoh media untuk menggambarkan kekuatan gempa.
Acara berikutnya adalah sesi tanya jawab. Tanya jawab berlangsung lama dan sangat antusias.

Para penanya mengaku puas dengan jawaban dan penjelasan yang disampaikan dan dapat mengerti apa yang disampaikan oleh presenter. Presentasi yang telah dilakukan oleh presenter pada kegiatan ini ni dianggap menarik oleh audienc.

\section{Hasil dan Pembahasan}

Penggunaan Microsoft Powerpoint sebagai media penyampaian informasi si dianggap sangat membantu dalam transfer of knowledge oleh para audiens. Video yang dipilih dirasakan sangat tepat untuk memberi contoh nyata peristiwa gempa bumi, tsunami likuifaksi maupun tanah longsor. Mekanisme fisik yang memicu terjadinya gempa bencana gempa Tsunami dan likuifaksi dapat dipahami dengan baik oleh audience.

Dengan kegiatan ini masyarakat merasa mendapatkan manfaat yang banyak yaitu pemahaman tentang bencana gempa bumi dan bencana sekunder pengikutnya yaitu tsunami likuifaksi dan tanah longsor sehingga mereka Paham cara mengatasi dan mempersiapkan diri jika terjadi bencana bencana tersebut

Dengan kegiatan ini masyarakat tidak lagi merasa khawatir secara berlebihan akan datangnya gempa dan tsunami yang jauh lebih besar sebagaimana yang diisukan akan terjadi akhir-akhir ini.

\section{Kesimpulan}

Kegiatan pengabdian pada masyarakat ini telah berjalan lancar sesuai dengan yang diharapkan. Hasil dari pengabdian pada masyarakat ini adalah meningkatnya pemahaman masyarakat akan bahaya gempa bumi, mekanisme penyebabnya dan cara mitigasinya.

Pemahaman masyarakat ini membawa dampak berkurangnya kekhawatiran yang berlebih akan datangnya gempa dan tsunami yang lebih besar, sehingga masyarakat dapat tetap melakukan kegiatan secara produktif. 


\section{Saran}

Kegiatan semacam ini perlu dilakukan dengan skala lebih besar untuk memberikan pemahaman yang benar tentang bencana gempa bumi dan bencana sekunder lainnya agar masyarakat dapat bersikap dengan tepat terhadap akan datangnya musibah berupa gempa dan bencana sekunder pengikutnya.

\section{Ucapan Terima Kasih}

Ucapan terima kasih kami haturkan kepada ada Bapak Dr. Joni Rohmat, Bapak Dr. Sugiman serta anggota masyarakat lain yang tidak dapat disebutkan satu persatu yang telah membantu pelaksanaan kegiatan pengabdian pada masyarakat ini.

\section{Daftar Pustaka}

Boomer, J.J., Rodriguez, C. E. 2002. Earthquakeinduced landslides in Central America, Engineering Geology. 63, p 189-220,

Kusnadi, C., dan Sutjipto B. 2013. Media Pembelajaran; Manual dan Digital. Jakarta: Penerbit Ghalia Indonesia.

Mahdavifar, M. R., Solaymani, S., Jafari, M. K. 2006. Landslides triggered by the Avaj, Iran earthquake of June 22, 2002. Engineering Geology 86, p. 166-182, 2006

Refice, A., Capolongo, D. 2002. Probabilistic modeling of uncertainties in earthquakeinduced landslide hazard assessment. Computers \& Geosciences. 28 p 735-749

Roestiyah. 2001. Strategi Belajar Mengajar. Jakarta: Penerbit Rineka Cipta

Syamsudin, Ashari, I., Adhi, M.A. 2018. Seismic Hazard and Microzonation Study of Tanjung Region, North Lombok (Indonesia) Using Microtremor Measurement. Jurnal Pendidikan Fisika Indonesia. 14 (2): 105110.

Zuhdi, M., Ardianto, T., Rokhmat, J., 2012. Pemodelan Komputer untuk Pemetaan Zona Rawan Bencana Tsunami di Pulau Lombok dan Pulau-Pulau Sekitarnya. Jurnal PIJAR. 2 (1)
Zuhdi, M., Taufik, M., Sutrio, Ayub, S., 2019. Pemodelan Sesar Pasca Gempa Dengan Inversi Data Gravitasi Time Lapse. Jurnal Pendidikan Fisika dan Teknologi. 5 (1), 156-161 